\title{
Elongation and Gravireactivity of Roots from an Agravitropic Maize Mutant: Implications of Growth Inhibitors ${ }^{1}$
}

\author{
Paul-Emile Pilet \\ Institute of Plant Biology and Physiology of the University, \\ 1005 Lausanne, 6, Pl. de la Riponne, Switzerland
}

\begin{abstract}
Growth of agravitropic (AGT) mutant (c.v. Kys) maize roots was significantly higher in comparison to that of two normal gravitropic cultivar roots. Vertical halfdecapitated roots bent towards the remaining half tip. This result can be explained by the fact that cap cells produced growth inhibitors (GI) moving in basipetal direction. The curvatures of half-decapitated roots in Kys AGT root were significantly smaller than in normal cultivar root. One essential consequence of this AGT mutation was brought by low GI content inside the extension zone.

Key words: Gravity effect - Growth inhibitors - Mutant - Root (maize) - Zea mays.
\end{abstract}

Growth inhibitors formed (or released) in the cap cells and moving in the basipetal direction appear to play an essential role in the regulation of the root elongation (Pilet 1980) and root gravitropism (Pilet 1977, 1981, Wilkins 1979). When maize roots were gravistimulated, these regulators were produced in larger amount in the lower part of the cap and a lateral transport in the apex occurred (Pilet 1976); they accumulate in the lower side of the growing zone (Pilet and Rivier 1981), inducing an unequal cell extension and consequnely a positive gravitropic response.

Some observations have already been reported on the gravireaction of roots of Pisum sativum ageotropium, in relation to their orientation with respect to gravity (Blixt et al. 1958), their metabolism (Schöldéen and Burström 1960), the geoelectric effect (Ekelund and Hemberg 1966), their growth (Olsen and Iversen 1980a) and their ultrastructure (Olsen and Iversen 1980b).

Enough caryopses from a mutant of Zea mays L. in the inbred line Kys (Kansas Yellow Saline), named AGT (agravitropic), were supplied by Dr. G. G. Doyle (University of Missouri, USA), and it is the aim of this study to investigate whether endogenous growth inhibitors are involved in the control of elongation and the loss of the gravireactivity in these Kys AGT maize roots.

\section{Materials and Methods}

Because it was not possible to have the normal "parent" of the agravitropic maize mutant, it was decided to compare the reactions of the Kys AGT roots to those of roots from two cultivars (LG 11, Orla 264) usually employed in our Institute and showing a strong gravireaction in light (Pilet 1976).

1 In honour of Professor J. Ashida

Abbreviations: AGT, agravitropic; GI, growth inhibitor(s). 
Pilet, P. E. (1979) Kinetics of the light-induced georeactivity of maize roots. Planta 145: 403-404.

Pilet, P. E. (1980) Hormonal control of root elongation: some light effects. In Plant Growth Substances. Edited by F. Skoog. p. 450-461. Springer Verlag, Berlin.

Pilet, P. E. (1981) Root cell gravireaction: Hormone interactions. The Physiologist 24S: 25-28.

Pilet, P. E. and M. C. Elliott (1981) Some aspects of the control of root growth and georeaction: the involvement of indoleacetic acid and abscisic acid. Plant Physiol. 67: 1047-1050.

Pilet, P. E. and L. Rivier (1981) Abscisic acid distribution in horizontal maize root segments. Planta 153: 453-458. Schöldéen, C. and H. Burström (1960) Physiological studies of an ageotropic pea mutant. Physiol. Plant. 13: 831838.

Shaw, S. and M. B. Wilkins (1973) The source and lateral transport of growth inhibitors in geotropically stimulated roots of Zea mays and Pisum sativum. Planta 109: 11-26.

Wilkins, M. B. (1979) Growth control mechanism in gravitropism. In Encyclopedia of Plant Physiology, New Series 7, Physiology of Movements. Edited by W. Haupt and M. E. Feinleib. p. 601-626. Springer Verlag, Berlin. 